\title{
Authoring Tool for Location-based Learning Experiences
}

\author{
Agustina M. Zimbello ${ }^{1}$, Federico M. Alconada Verzini ${ }^{1}$, Cecilia Challiol ${ }^{1,2}$, Alejandra B. Lliteras ${ }^{1,3}$, \\ Silvia E. Gordillo ${ }^{1,3}$ \\ ${ }^{1}$ UNLP, Facultad de Informática, LIFIA \\ ${ }^{2}$ CONICET \\ La Plata, Buenos Aires, Argentina \\ Argentina \\ ${ }^{3}$ CICPBA \\ Buenos Aires, Argentina \\ e-mails: \{azimbello, falconada, ceciliac, lliteras, gordillo\}@lifia.info.unlp.edu.ar
}

\begin{abstract}
In this paper, we present some features of our in-situ indoor-outdoor authoring tool for location-based learning experiences. For example, how to reuse locations in different experiences or how to design from scratch in places without any location sensing mechanisms. In addition, we describe some features in which we are working on. We expect to create a space for discussion about these kind of tools and to reflect on the products created with them.
\end{abstract}

Location-based Learning Experiences; In-situ Authoring Tool; Reuse Locations; Mobile Learning

\section{INTRODUCTION}

The technological advances have increased the scenarios of new learning practices [1]. In particular, location-based learning experiences allow learners to explore the environment and receive, on their mobile devices, learning activities in different locations. So, these kind of experiences are in-situ, what means that learning activities can be more challenging [1-2]. In some cases, the accuracy of the location is vital for the learner. For example, if the learner has to observe a specific plant, the activity should be triggered in front of it [1]. Then, some activities might require observing or manipulating physical objects in specific locations (as mentioned in [3]). This is why the design process has to consider not only location-based features but also physical objects.

Location-based learning experiences can be designed virtually or in-situ, as mentioned in [2]. Virtual design is based in a map to set the relevant locations in which the learners receive the learning activities [2]. On the other hand, in-situ design (as in [4]) implies visiting the real physical place, creating more precise experiences (by allowing teachers, for example, to observe the place from the learners ${ }^{6}$ perspective [5] or to better estimate the time to move from one location to another [6]). Note that all of these mentioned works are focused on outdoor experiences and contents are couple with GPS locations, hence, reuse of both contents and locations separately is not possible.

Some authors explore implications related to in-situ authoring in outdoor environments, as in [7], where it is mentioned that this is yet an open area to research. Moreover, in-situ indoor authoring tools have not been thoroughly researched so this is one of our motivations and why we are working on an in-situ indoor-outdoor authoring tool for location-based learning experiences which is an extension of [8].

The purpose of this paper is to create a space to discuss some features of the in-situ authoring tools. We use our authoring tool to show some features that we have been working on (e.g. reusable locations) and to describe a possible solution in places without location sensing mechanisms. Thus, the design is built from scratch. In addition, we hope that this paper could make a contribution to reflect on the products created with authoring tools (proceed from ad-hoc experiences to reusable solutions [9]).

The paper is structured as follows. In Section 2, we present and discuss some features of our in-situ indooroutdoor authoring tool for location-based learning experiences. Conclusions and some future works are presented in Section 3.

\section{IN-Situ AUTHORING TOOL}

In this section, we present and discuss some features of our in-situ authoring tool which is in an initial phase (only tested by developers). As mentioned before, it is an extension of [8], so it has been defined with a web responsive design. We use the concept of separation of concerns to define learning activities and locations. These concerns could be seen as separate layers that can be used in different location-based learning experiences. Then, each experience defines their points of interest (PoI) which associate learning activities with locations.

In Fig. 1 an example of a location layer inside of La Plata museum is shown. Each location is defined in an independent way, regardless of any domain or sensing mechanism and being able to reuse them in different location-based learning experiences (what is not possible on other existing tools such as [2] and [4]). So far, the tool uses an image to represent indoor spaces (as shown in Fig. 1), what can be easily done by teachers. In the future, we will expect to evolve to more precise representations such as, for example, Google Maps Indoor [10]. This begs the question: would these different space representations be easy to use by teachers in terms of the usability? And in a broader sense, how can these authoring tools be developed so as their users (e.g. teachers) do not require technical knowledge and can easily be used by them? 


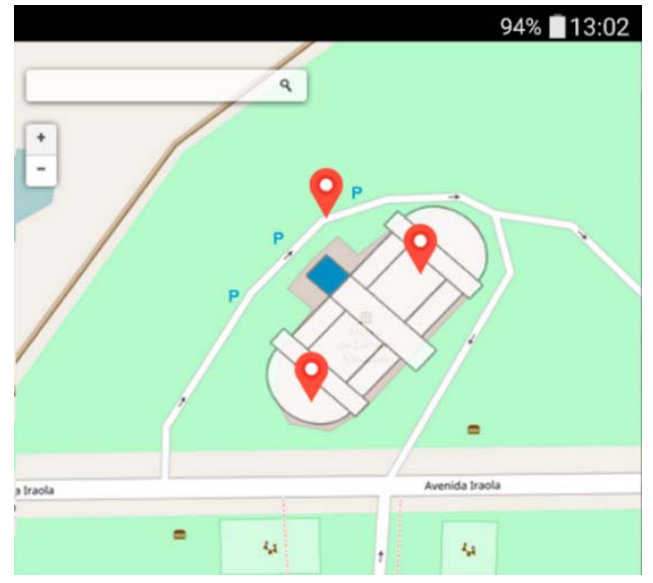

Figure 1. Example of location layer.

Our tool provides the possibility to set the mechanism to trigger learning activities for each location (currently, some locations could be triggered using GPS but others using QR codes). Then, this information is used in a location-based learning experience to trigger the learning activity in each location. These trigger mechanisms are defined in a separate layer, in order to reuse the location layer with different mechanisms on each experience. Suppose that in Fig. 1 the selected trigger mechanism for all locations is QR codes. Then, the tool will create as many QR codes as locations defined and teachers will be able to use these codes to set the physical place for each location. This is a simple way to create a location-based learning experience from scratch (for example, in places without any location sensing mechanisms). In addition, QR codes provide more accuracy to outdoor design by being able to observe a part of the physical place. Considering that indoor spaces may already count with sensing mechanisms, dynamically integrating them with these tools is definitely an open question.

Different structures to relate the contents have been identified in [11]. The current version of our tool provides the option to create linear, graph or set structures.

We have defined a model solution for location-based learning experiences which involves physical objects manipulation to resolve learning activities [12]. For the time being, our tool exports both content and location layers into XML files. We are working on integrating this model to generate executable experiences with our tool. Note that, the design of these specific learning activities requires to define a way to identify each physical object. To do that, we are developing a way to provide, from our tool, QR codes for each physical object associated to each learning activity. Using the prototype LearningPlaying ("Aprendo Jugando") defined in [12], we detected some templates related to these kind of experiences and we will be adding this as part of our tool to contribute on the creation and design.

\section{CONCLUSIONS AND FUtURE WORK}

In this paper, we have mentioned some features of our insitu indoor-outdoor authoring tool for location-based learning experiences. We have described how to use separation of concerns to reuse the locations in different experiences. In addition, we have presented the use of $\mathrm{QR}$ codes as a way to build from scratch in places without any location sensing mechanisms. Furthermore, we have described some features in which we are working on and we are planning to incorporate other ways of handling indoor positioning.

In the near future, we will organize some tests of proof with teachers to help us to complete the design of our tool (in a way that they are involved in the design process [5], in this case, in the one of our tool). We will analyze different roles identified with the design phase (as mentioned in [3], for example, learner, instructor, researcher and developer) and how these roles could be supported by our tool.

\section{REFERENCES}

[1] H.C. Chu, G.J. Hwang, C.C. Tsai, and J. Tseng, "A two-tier test approach to developing location-aware mobile learning systems for natural science courses," Computers \& Education, vol. 55, no. 4, Dec. 2010, pp. 1618-1627, doi: 10.1016/j.compedu.2010.07.004.

[2] P. Santos, D. Hernández-Leo, and J. Blat, "To be or not to be in situ outdoors, and other implications for design and implementation, in geolocated mobile learning," Pervasive and Mobile Computing, vol. 14, Oct. 2014, pp. 17-30, doi: 10.1016/j.pmcj.2013.09.001.

[3] E. Gilman, I.S. Milara, M. Cortés, and J. Riekki, "Towards user support in ubiquitous learning systems," IEEE Transactions on Learning Technologies, vol. 8, no. 1, Dec. 2015, pp. 55-68, doi: 10.1109/TLT.2014.2381467.

[4] F. Pittarello and L. Bertani, "Castor: Designing and experimenting a context-aware architecture for creating stories outdoors," Journal of Visual Languages \& Computing, vol. 25, no. 6, Dec. 2014, pp. 10301039, doi: 10.1016/j.jvlc.2014.10.013.

[5] R. Cober, E. Tan, J. Slotta, H.J. So, and K.D. Könings, “Teachers as participatory designers: Two case studies with technology-enhanced learning environments," Instructional Science, vol. 43, no. 2, Mar. 2015, pp. 203-228, doi: 10.1007/s11251-014-9339-0.

[6] T.Y. Hsu, C.K. Chiou, J.C. Tseng, and J.G. Hwang, "Development and evaluation of an active learning support system for context-aware ubiquitous learning," IEEE Transactions on Learning Technologies, vol. 9, no. 1, June 2016, pp. 37-45, doi: 10.1109/TLT.2015.2439683.

[7] D.E. Millard and C. Hargood, C., "Location Location Location: experiences of authoring an interactive location-based narrative," Proc. 9th International Conference on Interactive Digital Storytelling (ICIDS 2016), Springer, Nov. 2016, pp. 419-422, doi:10.1007/978-3319-48279-8_40.

[8] F.M. Alconada Verzini, J.I. Tonelli, C. Challiol, A.B. Lliteras, and S.E. Gordillo, "Authoring tool for location-aware experiences," Proc. 2015 Workshop on Narrative \& Hypertext (NHT '15), ACM, Sep. 2015, pp. 21-25, doi: 10.1145/2804565.2804570.

[9] D. Weyns, M. Caporuscio, B. Vogel, and A. Kurti, "Design for Sustainability $=$ Runtime Adaptation $\cup$ Evolution," Proc. 2015 European Conference on Software Architecture Workshops (ECSAW '15), ACM, Sep. 2015, pp.62-69, doi: 10.1145/2797433.2797497.

[10] https://www.google.com/maps/about/partners/indoormaps

[11] C. Hargood, V. Hunt, M.J. Weal, and D.E Millard, "Patterns of sculptural hypertext in location based narratives," Proc. 27th ACM Conference on Hypertext and Social Media (HT '16), ACM, July 2016, pp. 61-70, doi: 0.1145/2914586.2914595.

[12] A.B. Lliteras, "Un enfoque de modelado de actividades educativas posicionadas que contemplan elementos concretos," Master Thesis, Faculty of Informatics, National University of La Plata, Argentina, Nov. 2015, http://hdl.handle.net/10915/50030 